\title{
Analisis Etnomatematika Pada Kerajinan Anyaman Bambu Terhadap Pemebelajaran Matematika di Kabupaten Sukabumi
}

\author{
Nina Sri Wahyuni \\ Pendidikan Matematika, Fakultas Keguruan dan Ilmu Pendidikan, Universitas Mughammadiya Sukabumi \\ Email : ninasriwahyuni713@gmail.com
}

\begin{abstract}
Abstrak
Pembelajaran matematika tidak hanya tentang rumus maupun teori melainkan dapat dilakukan dengan banyak cara salah satunya melalui kerajinan anyaman bambu. Kerajinan anyaman bambu ini diantaranya nyiru, aseupan, hihid dan boboko yang bertujuan untuk mengetahui manfaatnya untuk pembelajaran matematika. Metode yang digunaan penulis dalam penulisan artikel ini adalah studi pustaka melalui internet dan peralatan rumah tangga dari anyaman bambu yang terdapat di rumah, dari peristiwakerajinan anyaman bambu tersebut terdapat beberapa konsep matematis yang diberikan salah satunya pembelajaran bangun datar dan bangun ruang, konsep tersebut dapat dikaitan terhadap pembelajaran matematika salah satu dalam pengkajian soal cerita guna memperkenalkan etnomatematika.
\end{abstract}

Kata Kunci : Etnomatematika, Pembelajaran Matematika, Kerajinan Anyaman Bambu.

\section{PENDAHULUAN}

Kerajinan di Indonesia terbuat dari berbagai macam bahan diantaranya rotan, bambu, pandan, dan lainnya. Menurut P.Sopamena \& R.Yapono 2016 mengungkapkan "belajar matematika bukan hanya tentang mendapatkan dan menguasai komputasi dan teknik pemecahan masalah, atau semata-mata tentang pemahaman definisi, argumen dan bukti”. Pendidikan dan kebudayaan merupakan bagian yang tidak dapat dipisahkan, keduanya saling mendukung dan menguatkan (Aprilianti, Indri dkk 2019). Nur Prabawati, Mega 2016 mengungkapkan "matematika dianggap sebagai sesuatu yang netral dan terbebas dari budaya (culturraly-free)".

Masyarakat sering tidak menyadari bahwa mereka telah menggunakan matematika di dalam kebudayaan (Huda et al., 2020; Komarudin \& Permana, 2019). Matematika yang terdapat dalam suatu kebudaaan tertentu dikenal dengan istilah Etnomatematika. Kadek dan I Gusti 2018 mengungkapkan "Etnomatematika merupakan matematika yang muncul sebagai akibat pengaruh kegiatan yang ada di lingkungan yang dipengaruhi oleh budaya". Etnomatematika sering disebut sebagai pembelajaran yang berbasis budaya.

Etnomatematika adalah berbagai hasil aktivitas matematika yang dimiliki atau berkembang di masyarakat (Aini et al., 2018; Rohmaini et al., 2020), meliputi konsep-konsep matematika yang terdapat pada peninggalan sejarah dan kerajinan tangan berupa candi dan prasasti, gerabah dan peralatan tradisional, satuan lokal, motif kain batik dan bordir, permainan tradisional, serta pola pemukiman masyarakat (Moh. Zayyadi., 2017). Etnomatematika merupakan representasi kompleks dan dinamis yang menggambarkan pengaruh kultural penggunaan matematika dalam aplikasinya (Hartoyo, Agung 2012).

Berdasarkan latar belakang diatas, maka rumusan masalah pada artikel ini adalah pemanfaatan etnomatematika pada pembelajaran matematika. Tujuan artikel ini untuk mengetahui unsur matematika apa saja yang terdapat pada anyaman bambu (Nyiru, Aseupan, Hihid dan Boboko). Bahan yang digunakan pada anyaman ini adalah bambu. Menganyam merupakan teknik menyilangkan atau menumpang tindihkan bahas sebagai dasar menganyam dengan bahas yang dimasukan untuk menganyam. Sebelum itu bahan bambu yang digunakan untuk menganyam dikeringkan terlebih dahulu agar semakin lentur dan tidak mudah berjamur. Pola menganyam tiap daerah relatif sama.

Hasil dari menganyam bambu ini salah satunya alat- alat rumah tangga seperti yang di bahas penulis yaitu Nyiru, Aseupan, Hihid dan Boboko. Kaitan nyiru dengan pembelajaran matematika adalah karena nyiru yang berbentuk lingkaran sehingga dapat dikaitkan dengan materi bangun datar lingkaran. Kaitan aseupan dengan pembelajaran matematika adalah aseupan yang berbentuk kerucut tanpa tutup sehingga aseupan dapat dikaitkan dengan materi bangun ruang 
kerucut. Kaitan Hihid/ Kipas dengan pembelajaran matematika adalah karena hihid yang berbentuk persegi pada kipasnya dan persegi panjang pada pegangan hihidnya sehingga dapat dikaitkan dengan materi bangun datar persegi dan persegi panjang. Kaitan Boboko dengan pembelajaran matematika adalah badan boboko yang berbentuk menyerupai tabung tanpa alas boboko berbentuk kubus/ persegi sehingga boboko dapat dikaitkan dengan materi bangun ruang juga bangun datar.

Berdasarkan pendahuluan diatas jelas bahwa matematika bukan hanya sekedar dalam teori saja, tetapi matematika juga dapat ditemukan dalam kebudayaan. Adanya matematika yang bernuansa budaya penulis berharap memberikan kontribusi yang sangat besar dalan pembelajaran matematika yang membosankan menjadi lebih menarik dan membuat siswa antusias terhadap pembelajaran matematika.

\section{METODE}

Artikel ini ditulis dengan menggunakan metode studi pustaka yang merupakan telaah dari literatur dari jurnal, internet dan benda-benda anyaman bambu dilingkungan sekitar lingkungan yang ada hubungannya dengan etnomatematika. Teknik analisis data dengan merangkum, menyajikan data dan memberi kesimpulan.

\section{HASIL DAN PEMBAHASAN}

Salah satu hasil kreativitas manusia adalah menciptakan sesuatu sesuai dengan kebutuhannya dengan menggunakan tangannya sendiri sehingga manusia mendapat pengalaman dari tangannya tersebut (Kadek \& I Gusti 2014; Komarudin et al., 2014). Dengan pengalaman yang diperoleh, manusia dapat memiliki ketrampilan sesuai dengan dirinya. Ketrampilan mengayam dapat dilakukan oleh semua orang. Akan tetapi kerajian hasil anyaman, motif dan teknik mengayam bergantung dari tangan si pengayam. Seni menganyam atau disebut seni merajut adalah salah satu bentuk seni kriya (Isnaini, Lailan 2019).

Kerajinan menganyam adalah teknik menghubungkan dua atau lebih benda atau bahan untuk mengayam dengan cara saling menyilangkan sehingga tidak saling lepas (Anandhita, Gustav 2017). sudah ada sejak zaman nenek moyang dan sampai sekarang masih ada. Tiap daerah memiliki kerajinan anyaman yang berbeda-beda. Di bawah ini akan dikupas kerajian anyaman dari Kabupaten Sukabumi. Kerajinan Anyaman Sukabumi diantaranya nyiru, aseupan, hihid dan boboko.
Anyaman bambu di Sukabumi memiliki bentuk yang bermacam-macam. Ada yang berbentuk bangun datar maupun bangun ruang. Kipas/ Hihid merupakan salah satu contoh yang berbentuk dua dimensi. Untuk yang tiga dimensi contohnya kukusan/ Asepan. Kerajinan anyaman di Sukabumi masih digunakan untuk perabot rumah tangga. Dibawah ini merupakan empat jenis benda yang terbuat dari anyaman bambu di Sukabumi diantaranya :

\section{a. Nyiru}

Pengertian Nyiru menurut KBBI adalah alat rumah tangga, berbentuk bundar/ lingkaran, dibuat dari bambu yang dianyam, gunanya untuk menampi beras dan sebagainya. Nyiru adalah alat yang terbuat dari anyaman belahan batang pohon bambu yang di belah yang berbentuk bundar seperti piring berdiameter antara 65-80 $\mathrm{cm}$. Alat ini biasanya digunakan untuk menampi beras dll. Nyiru memiliki bentuk lingkaran, memiliki diameter dan jari- jari sehingga bentuk dari nyiru dapat dikaitkan dengan konsep bangun datar yaitu lingkaran. Misalkan kita dapat memberikan tugas kepada siswa untuk mengukur luas dan keliling nyiru yang ada dirumah masing-masing.

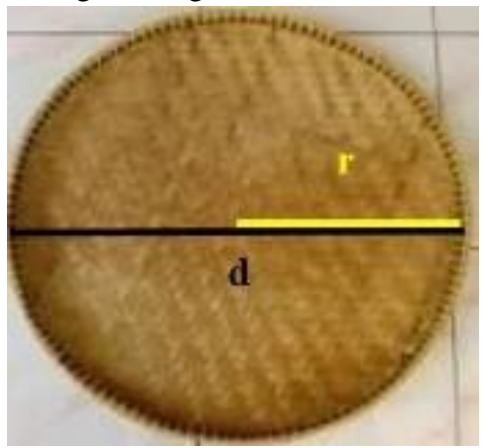

Gambar 1. Nyiru

Unsur-unsur Lingkaran Matematika

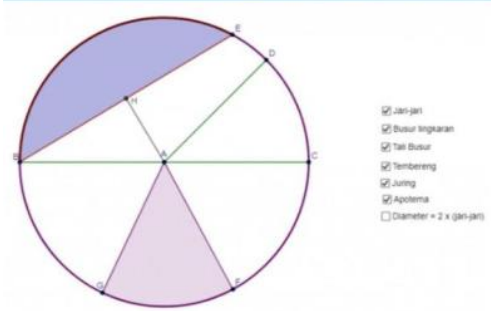

Gambar 2 Unsur Lingkaran

Rumus luas lingkaran $=\pi r^{2}$.

Rumus keliling lingkaran $=2 . \pi \cdot r$

atau $\pi . d$

Diameter : $d=2 . r$

Jari-jari : $r=\frac{d}{2}$ 
Contoh Soal 1.

Diketahui sebuah nyiru memiliki

diameter $42 \mathrm{~cm}$. Tentukan luas

nyiru tersebut?

Penyelesaian

Diketahui :

$d=42 \mathrm{~cm} ; r=\frac{d}{2}=\frac{42}{2}=21 \mathrm{~cm}$

Ditanyakan : Luas nyitu ?

Jawab :

Luas Nyiru $=\pi r 2=\frac{22}{7} \times 21 \times$

$21=1.386 \mathrm{~cm}$

Jadi luas nyiru tersebut adalah

$1.386 \mathrm{~cm}$

\section{b. Aseupan}

Pengertian Asepan (Aksara Sunda) atau kukusan adalah suatu wadah untuk mengukus nasi atau makanan lain. Aseuan berbentuk kerucut dan terbuat dari bambu yang dianyam. Oleh sebab itu pada zaman dahulu hampir di setiap dapur masyarakat sunda selalu didapati aseupan. Aseupan memiliki bentuk tiga dimensi seperti kerucut tanpa tutup alas, sehingga bentuk dari aseupan dapat dikaitkan dengan konsep bangun ruang yaitu kerucut tanpa alas. Misalkan kita dapat memberikan tugas kepada siswa untuk mengukur volume dan luas permukaan aseupan atau menghitung luas dan keliling aseupan yang ada dirumah masing-masing. Kaitan aseupan dengan matematika yakni :

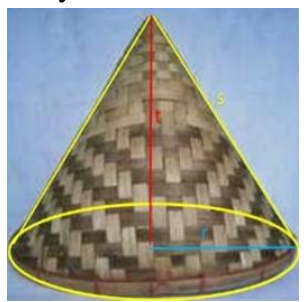

Gambar 3. Aseupan
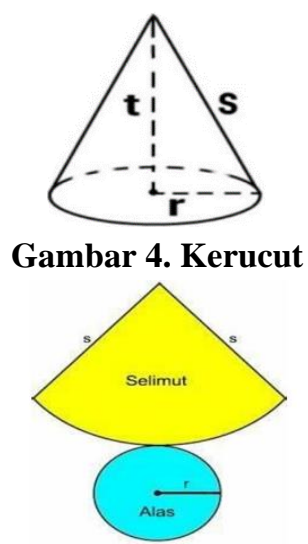

Gambar 5. Alat dan Selimut Kerucut

Keterangan :

$$
\begin{aligned}
& r=\text { jari-jari } \mathrm{t}=\text { tinggi } \\
& s=\text { selimut } \mathrm{d}=\text { diameter } \\
& \pi=\frac{22}{7} \text { atau } 3,14
\end{aligned}
$$

\section{Contoh Soal 2}

Hitunglah luas selimut dan volume sebuah miniatuer aseupan jika diketahui jari-jarinya 7 $\mathrm{cm}$, selimut $14 \mathrm{~cm}$ dan tinggi $7 \mathrm{~cm}$ !

Jawab :

Luas selimut : $\pi \times r \times s=\frac{22}{7} \times 7 \times 14=$ $308 \mathrm{~cm}$

Volume $: \frac{1}{3} \times \pi \times r^{2} \times t$

$=\frac{1}{3} \times \frac{22}{7} \times 7^{2} \times 14=308 \mathrm{~cm}$

Jadi luas selimut miniatur aseupan tersebut adalah $308 \mathrm{~cm}$ dan volume miniatur aseupan tersebut adalah $462 \mathrm{~cm}$.

\section{c. Hihid}
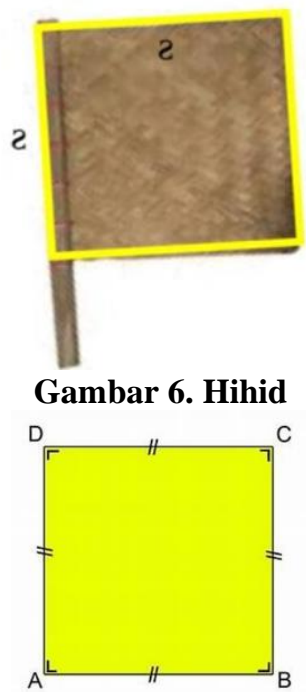

\section{Gambar 7. Persegi}

Hihid (aksara Sunda) adalah alat untuk mengipas nasi pada waktu di akeul (nasi panas yang di aduk- aduk). Hihid memiliki bentuk persegi empat, terbuat dari bambu yang dianyam dan salah satu sisi panjang di beri bingkai bilah bambu sebagai pegangan. Selain digunakan untuk mengipas nasi hihid juga bisa digunakan untuk mengipas bara api, sate, dll. Hihid memiliki bentuk persegi empat pada anyamannya sehingga bentuk dari hihid dapat dikaitkan dengan konsep bangun datar yaitu persegi empat. Misalkan kita dapat memberikan tugas kepada siswa untuk mengukur luas atau keliling dari anyaman hihid beserta pegangan 
bambu hihid yang ada dirumah masing-masing. Kaitan hihid dengan matematika adalah :

Rumus persegi :

Luas $=s \times s$

Keliling $=4 \times s$

Sisi $=\sqrt{s}$ atau $\frac{\text { keliling }}{4}$

Diagonal $=\sqrt{2 \times s^{2}}$

Keterangan

$\mathrm{S}=$ Sisi

contoh Soal 3

Guru menugaskan kepada siswanya agar membuat sebuah hihid dengan panjang sisi 20 $\mathrm{cm}$. Carilah luas dan keliling hihid tersebut!

Jawab :

Diketahui : $s=20$

Luas hihid $=s \times s=20 \times 20=400 \mathrm{~cm}$

Keliling Hihid $=4 \times s=4 \times 20=80 \mathrm{~cm}$

\section{d. Boboko}

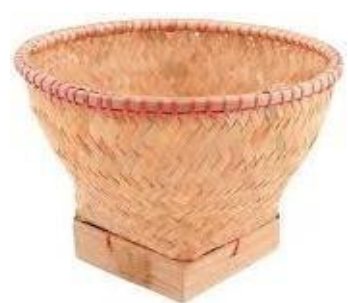

\section{Gambar 8. Boboko}

Boboko adalah suatu tempat untuk mencuci beras atau wadah nasi. Boboko terbuat dari bambu yang dianyam rapat, berbentuk bundar cembung dengan kaki segi empat yang disebut soko. Sisi permukaan wadah diberi wengku yang dililitkan dengan bambu tali. Pada masyarakat Sunda, boboko digunakan juga untuk menyimpan barang makanan yang akan dikirimkan ke tetangga atau saudara.

Boboko memiliki permukaan yang berbentuk lingkaran dan alas berbentuk persegi / kubus sehingga bentuk dari boboko dapat dikaitkan dengan konsep bangun datar yaitu lingkaran dan persegi dan bangun ruang yaitu kubus. Misalkan kita dapat memberikan tugas kepada siswa untuk mengukur luas / keliling dari permukaan boboko dan alas boboko yang ada dirumah masing-masing. Kaitan boboko dengan matematika adalah :

\section{Permukaan Boboko}

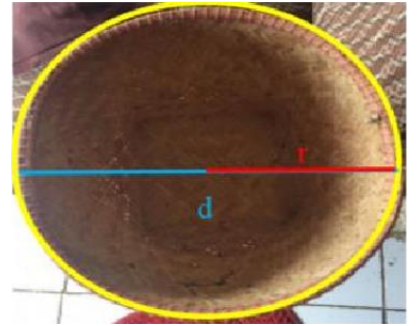

Gambar 9. Permukaan Boboboko

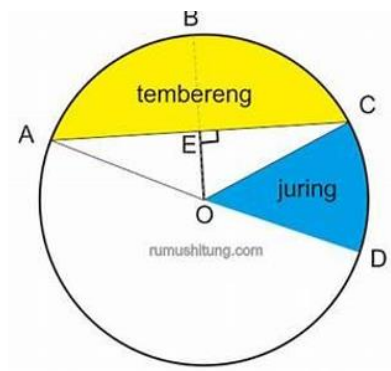

Gambar 10. Lingkaran

Rumus luas lingkaran $=\pi r 2$.

Rumus keliling $=2 . \pi$. $r$ atau $\pi . d$

Diameter : $d=2 . r$

Jari-jari : $r=\frac{22}{7}$

Keterangan :

$r=$ Jari-jari

$d=$ diameter

$\pi=\frac{22}{7}$ atau 3,14

\section{Alas Boboko}

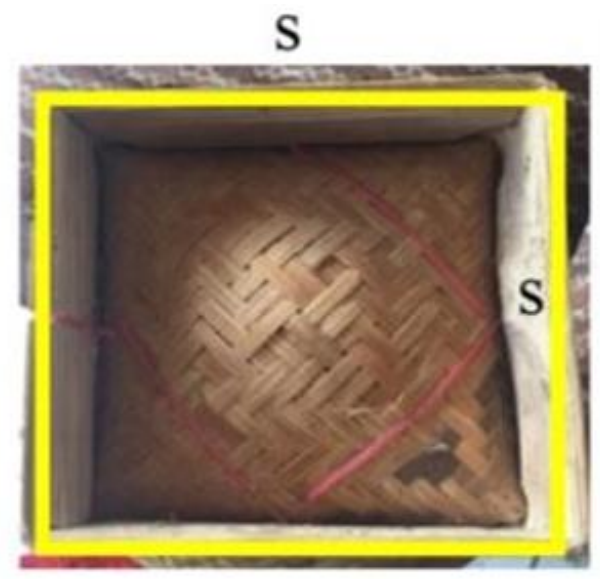

Gambar 11. Alas Boboko

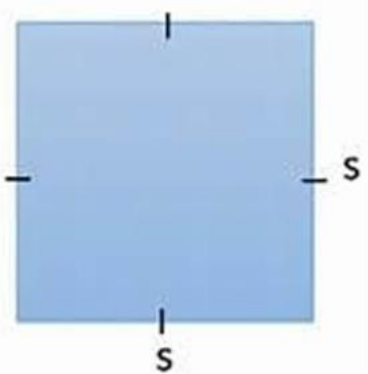

Gambar 12. Persegi

Rumus persegi :

Luas $=s \times s$ 
Keliling $=4 \times s$

Sisi $=\sqrt{s}$ atau $\frac{\text { keliling }}{4}$

Diagonal $=\sqrt{2 \times s^{2}}$

Keterangan

$\mathrm{s}=$ Sisi

\section{Alas Boboko}

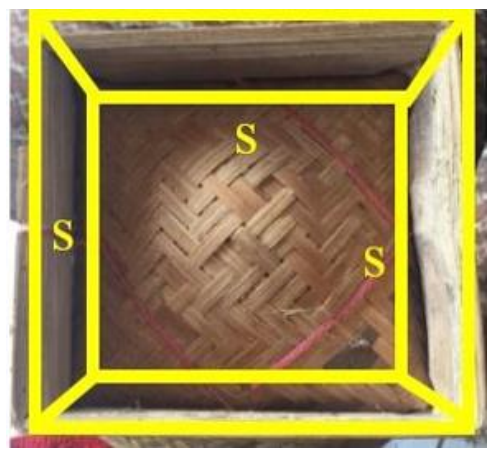

Gambar 11. Alas Boboko

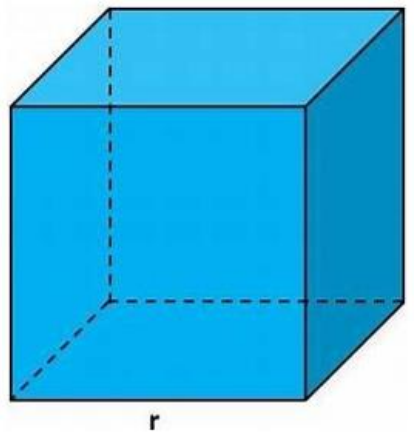

Gambar 12. Persegi

Rumus Kubus Volume $V=$ S.S. $S$

Luas Permukaan Kubus $L=$

6. (s.s) Keliling $(K)=12 . s$

Luas salah satu sisi $=s . S$

Hasil dari menganyam bambu ini salah satunya alat- alat rumah tangga seperti yang di bahas penulis yaitu Nyiru, Aseupan, Hihid dan Boboko. Kaitan nyiru dengan pembelajaran matematika adalah karena nyiru yang berbentuk lingkaran sehingga dapat dikaitkan dengan materi bangun datar lingkaran. Kaitan aseupan dengan pembelajaran matematika adalah aseupan yang berbentuk kerucut tanpa tutup sehingga aseupan dapat dikaitkan dengan materi bangun ruang kerucut. Kaitan Hihid/ Kipas dengan pembelajaran matematika adalah karena hihid yang berbentuk persegi pada kipasnya dan persegi panjang pada pegangan hihidnya sehingga dapat dikaitkan dengan materi bangun datar persegi dan persegi panjang. Kaitan Boboko dengan pembelajaran matematika adalah badan boboko yang berbentuk menyerupai tabung tanpa alas boboko berbentuk kubus/ persegi sehingga boboko dapat dikaitkan dengan materi bangun ruang juga bangun datar.

\section{PENUTUP}

\section{Simpulan}

Hasil dari analisis kerajinan ayaman bambu yang telah dilakukan dapat disimpulkan bahwa terdapat etnomatematika dari setiap benda yang diteliti yang memuat beberapa konsep pemelajaran matematika yang dapat di aplikasikan di tingkat SD/MI dan SMP/ MTS diantanya :

a. Nyiru memiliki bentuk lingkaran, memiliki diameter dan jari- jari sehingga bentuk dari nyiru dapat dikaitkan dengan konsep bangun datar yaitu lingkaran.

b. Aseupan memiliki bentuk tiga dimensi sehingga bentuk dari aseupan dapat dikaitkan dengan konsep bangun ruang yaitu kerucut tanpa alas dan bangun datar yaitu segitiga.

c. Hihid memiliki bentuk persegi empat pada anyamannya sehingga bentuk dari hihid dapat dikaitkan dengan konsep bangun datar yaitu persegi empat.

d. Boboko memiliki permukaan yang berbentuk lingkaran dan alas berbentuk persegi / kubus sehingga bentuk dari boboko dapat dikaitkan dengan konsep bangun datar yaitu lingkaran dan persegi dan bangun ruang yaitu kubus.

\section{Saran}

Berdasarkan hasil dari analisi saran yang dapat kemukakan oleh peneliti adalah diharapkan dapat melakukan penelitian yang lebih baik dan dapat lebih mengembangkan peran etnomatematika dalam pembelajaran matematika lainnya.

\section{DAFTAR PUSTAKA}

Aprilianti, I ., Sunardi, dkk "Etnomatematika pada Aktivitas Petani Kakao Desa Temuasri Sempu Banyuwangi sebagai Bahan Ajar Siswa". Saintifika. 21 (1) (2019).

Fitroh, Wahyu,dkk. "Peran Matematika dan Pembelajaran Dalam Mengembangkan Kearifan Budaya Lokal Mendukung Pendidikan Karakter Bangsa". Prosiding Seminar Nasional 2016 Program Studi 
Pendidikan Matematika Universitas Madura, Madura (2015).

Junaidi, Lalu Alwan; dkk Etnomatematika Masyarakat Pengrajin Anyaman Budiarto, Mega Teguh. (2015).

Aini, E. P., Masykur, R., \& Komarudin, K. (2018). Handout Matematika berbantuan Etnomatematika Berbasis Budaya Lokal. Desimal: Jurnal Matematika, 1(1), 73-79. https://doi.org/10.24042/djm.v1i1.1950

Huda, S., Suherman, S., Komarudin, K., Syazali, M., \& Umam, R. (2020). The Effectiveness of Al-Qurun Teaching Model (ATM) Viewed from Gender Differences: The Impact on Mathematical Problem-Solving Ability. https://doi.org/doi:10.1088/17426596/1467/1/012001

Komarudin, K., \& Permana, P. T. (2019). LKPD Berbasis Scientific Approach Terhadap Kemampuan Pemecahan Masalah Matematis Peserta Didik Sekolah Dasar. TERAMPIL: Jurnal Pendidikan Dan Pembelajaran Dasar, 6(1), 79-91. https://doi.org/10.24042/terampil.v6i1.438 5

Komarudin, K., Sujadi, I., \& Kusmayadi, T. A. (2014). Proses Berpikir Kreatif Siswa SMP Dalam Pengajuan Masalah Matematikaditinjau Dari Gaya Kognitif Siswa (Studi Kasus Pada Siswa Kelas Viiih SMP Negeri 1 Sukoharjo Tahun Pelajaran 2012/2013). Jurnal Pembelajaran Matematika, 2(1).

Rohmaini, L., Netriwati, N., Komarudin, K., Nendra, F., \& Qiftiyah, M. (2020). Pengembangan Modul Pembelajaran Matematika Berbasis Etnomatematika Berbantuan Wingeom Berdasarkan Langkah Borg And Gall. Teorema: Teori Dan Riset Matematika, 5(2), 176-186.

Lipka, Jerry dan Andrew-Irkhe, dkkIdentifikasi Pembelajaran Matematika Dalam Tradisi Melemang di Kabupaten Kerinci Provinsi Jambi. Seminar Prosiding Nasional Matematika dan Pendidikan UMS 2015. Surakarta. Hal 334- 344,(2019).

Sarwoedi, Sarwoedi, "Efektifitas Etnomatematika Dalam Meningkatkan Kemampuan Pemahaman. 